\title{
Effect of Proteolytic Agents on Microleakage of Etch and Rinse Adhesive Systems
}

Shahin Kasraei', Ebrahim Yarmohammadi ${ }^{2}$, Maryam Farhadian ${ }^{3}$, Mona Malek ${ }^{4 *}$

1 DDS, MS, Professor, department of Restorative dentistry,dental school, Shahid Beheshti university of medical sciences, Tehran,Iran Email address; sh_kasraie@yahoo.com.

2 DDS, MS, Assistant

professor, department of restorative dentistry, Hamedan university of medical science, Hamedan,Iran. Email address; yarmohammadi1380@yahoo.com

${ }^{3}$ Phd, Assistant professor Department of Biostatistics,School of Public Health and Research Center for Health Sciences, Hamadan University of Medical Sciences,Hamadan,Iran. Email address; maryam farhadian80@yahoo.com

${ }^{4}$ DDS, MS , Department of restorative dentistry,Hamedan university of medical science, Hamedan, Iran.

Corresponding author Mona Malek

Hamadan University of medical sciences, Hamadan, Iran

E-mail: mona_mlk@yahoo.com

Received: May 13, 2017

Accepted: September 14, 2017

\section{(i)}

Aim: this study aimed to assess the effect of treatment of phosphoric acid etched dentin surface with $5 \%$ bromelain enzyme and Nd:YAG laser prior to the use of etch and rinse adhesive systems on microleakage margins of class $V$ composite restorations. Materials and Methods: sixty sound premolar teeth were selected. Standard class $V$ cavities were prepared in the buccal and lingual surfaces of each teeth. Preparation in that way $1 \mathrm{~mm}$ of the cavity was above and 1 $\mathrm{mm}$ of it was below the cementoenamel junction. The teeth were then randomly divided into three groups including 20 teeth (40cavities in each gorup). Two ethanol base etch and rinse system (Adper Single Bond and OptiBond Solo) was applied in each group. In the control group, cavities were etched with $37 \%$ phosphoric acid. Adper Single Bond was applied to 20 and OptiBond Solo was applied to the remaining 20 cavities and they were restored with Z250 composite $(n=40)$. The same procedures were performed in bromelain and Nd:YAG laser groups with the difference that prior to the application of adhesive, aqueous $5 \%$ bromelain was applied in bromelain group while Nd:YAG laser was irradiated in laser group. All teeth were thermocycled and their apices were sealed with sticky wax. The tooth surfaces were coated with nail varnish except for $1 \mathrm{~mm}$ around the restoration margins, and the teeth were then immersed in fuchsine and sectioned by a diamond disc into mesial and distal halves. Marginal microleakage at both sides was determined and scored under a stereomicroscope at x40 magnification. Then data were analyzed using the Kruskal Wallis and Mann Whitney tests $(a=0.05)$. Results: according 
the result of Mann Whitney test, Cervical margins showed significantly higher microleakage than the occlusal margins $(P=0.000)$ but no significant difference was noted in microleakage of occlusal $(P=0.362)$ or gingival $(P=0.147)$ margins among the three groups by Kruskal Wallis test. Conclusion: in conclusion, application of proteolytic agents(5\% bromelain solution and Nd:YAG laser) on acid-etched dentin surface prior to the application of adhesive has no significant effect on marginal microleakage of class $\mathrm{V}$ composite restorations.

Keywords: Microleakage. Bromelain. Laser. Etch and Rinse Bonding Agents.

\section{Introduction}

The integrity of adhesive resin bond to dentin plays an important role in success of composite restorations ${ }^{1-4}$. The hybrid layer is the most important structure affecting micromechanical retention of resin restorations and sealing of dentin. However, the hybrid layer and the adhesive interface is the most common site of failure of these restorations ${ }^{5,6}$. Proper bond of adhesive resin to dentin depends on many factors such as removal of minerals from dentin substrate, wetting of the substrate with adhesive and penetration of adhesive into demineralized dentin?

Acid etching completely demineralizes a few micrometers of dentin surface and exposes the collagen fibers ${ }^{3,7}$. In etch and rinse adhesives, a reduction in concentration gradient of monomer is noted by an increase in penetration depth of resin into demineralized dentin. The highest concentration of resin is found at the surface. The hybrid layer has a lower concentration of resin and the least concentration is found at the deepest part of the demineralized dentin ${ }^{8,9}$. The discrepancy between the depth of dentin demineralization and penetration depth of resin results in nano-leakage in deep, water-rich parts of the hybrid layer ${ }^{8-11}$. Moreover, outward movement of fluid in dentinal tubules of vital teeth decreases resin penetration into collagen matrix, causing weak points in the hybrid layer ${ }^{8,9}$. Nano-leakage in this area results in enzymatic degradation and hydrolysis of resin or collagen and undermining of hybrid layer and derangement of collagen fibers ${ }^{12}$.

Type one collagen is the most abundant organic component in extracellular matrix of dentin. It plays an important role in formation of hybrid layer and adhesion to dentin structure. Aside from type one collagen, non-collagen proteins such as proteoglycans and glycoproteins are also present in spaces between collagen fibers ${ }^{13-16}$. Covering the etched dentin surface with these compounds can decrease the penetration of large molecules (Bis-GMA) into dentin, and only smaller molecules such as HEMA can penetrate deep into dentin ${ }^{8}$. HEMA-rich areas in the hybrid layer have high strain, causing fatigue of collagen fibrils and making them susceptible to degradation ${ }^{8}$. Therefore, recent studies have focused on improving the quality of the hybrid layer by removing the demineralized collagen network and enhancing further penetration of resin into acid-etched areas $1,2,8,17$. Materials used for this purpose often have shortcomings such as toxicity and instability ${ }^{18}$ or require long-term use, which limits their application in the clinical setting ${ }^{19-22}$. Materials used for this purpose must save time in the clinical setting, have low cytotoxicity and protect the resin-dentin interface ${ }^{23}$. 
Some previous studies discussed that removal of collagen network by use of proteolytic enzymes such as collagenase or bromelain may increase the bond strength and decrease marginal microleakage of composite restorations ${ }^{3,17}$. It appears that decreased dentin microleakage following the use of bromelain is due to the ability of this enzyme to remove the residual proteins and collagen network after etching ${ }^{3}$.

Since the etching of dentin surface with phosphoric acid lead to dissolving inorganic component of smear layer and remaining amorphous protein layer. This surface collagen smear decrease the rate of resin monomer penetration and form weak hybrid layer that affect the composite bond ${ }^{8}$. Bromelain solution can eliminate collagen smear layer and organic component from surface of dentin substrate and increase resin penetration into dentin , improve the quality of hybrid layer and decrease microleakage ${ }^{3}$.

$\mathrm{Nd}$ :YAG laser is an electromagnetic infrared radiation with $1065 \mathrm{~nm}$ wavelength. It can selectively ablate the collagen network ${ }^{3}$ and deproteinize dentin without affecting its mineral content ${ }^{1,3}$. Opening of dentinal tubules and absence of smear layer on the surface increase the bond strength of composite to laser-treated dentin surface ${ }^{1}$.

This study aimed to assess dentin surface treatment methods to enhance further resin penetration into the etched dentin surface and facilitate the bonding process in the clinical setting. The null hypothesis was that dentin preparation with $5 \%$ bromelain and Nd:YAG laser irradiation prior to the application of etch and rinse (Adper Single Bond and OptiBond Solo) adhesive systems would have no effect on occlusal and marginal microleakage in class $\mathrm{V}$ composite restorations.

\section{Materials and Methods}

This study was performed on 60 sound human premolars with no carious lesions, occlusal wear or previous restorations. The teeth had been extracted within the past three months for orthodontic reasons and had stored in $0.2 \%$ thymol solution. One week before the experiment, the teeth were transferred to distilled water. Standard class $\mathrm{V}$ cavities measuring $3 \mathrm{~mm}$ mesiodistally and $2 \mathrm{~mm}$ occluso-gingivally with $1.5 \mathrm{~mm}$ depth were prepared on buccal and lingual surfaces of each tooth according to ISO/TS11405 using 008/835 diamond bur (Microdont, New York, USA) and high speed hand piece under water and air spray by a single operator such that $1 \mathrm{~mm}$ of the cavity was above and $1 \mathrm{~mm}$ of it was below the cementoenamel junction. Occlusal margin was beveled by $0.5 \mathrm{~mm}$. The teeth were then randomly divided into three groups $(n=20)$. Each tooth had two class $V$ cavities (one in the buccal and one in the lingual surface; a total of 40 cavities). Groups were prepared as follows:

Control group: The enamel margin of the cavities was etched for 30 seconds. Dentin was etched for 15 seconds using 37\% phosphoric acid (Gel Etchant, Kerr SPA, Salerno, Italy). The cavities were rinsed for 60 seconds and excess water was removed by a cotton pellet. In 20 cavities, Adper Single Bond (3M ESPE, St. Paul, MN, USA) was applied on cavity walls according to the manufacturer's instructions in two layers and gently air sprayed for 5 seconds in order for the solvent to evaporate; 10 seconds of light curing was then performed using a light curin unit Bluephase; Ivoclar Vivadent, Schaan, Lichtenstein) with a light intensity of $1200 \mathrm{~mW} / \mathrm{cm}^{2}$. In the remaining 20 cavities, OptiBond Solo (Kerr SPA, Salerno, Italy) was applied by an applicator on cavity walls according to the manufactur- 
er's instructions and gently air sprayed for 3 seconds followed by 20 seconds of light curing. A3 shade of Z250 microhybrid methacrylate composite (3M ESPE, St. Paul, MN, USA) was applied by a spatula in three increments in the gingival, occlusal and middle areas. Each segment was separately cured for 20 seconds using a light curing unit (Bluephase; Ivoclar Vivadent, Schaan, Lichtenstein) with a light intensity of $1200 \mathrm{~mW} / \mathrm{cm}^{2}$. After completion of restoration, post-curing was performed for 40 seconds.

Bromelain group: In this group, $5 \%$ bromelain solution was applied after acid etching of the cavity. To prepare $5 \%$ bromelain, $5 \mathrm{~g}$ of bromelain powder was dissolved in $100 \mathrm{cc}$ of distilled water. The solution was applied by an applicator on cavity surfaces, allowed 30 seconds, rinsed with water for 15 seconds and excess water was removed by cotton pellet. Bonding agent and composite were applied as in the control group.

Nd:YAG laser group: After acid etching (similar to the control group), the teeth were subjected to Nd:YAG laser irradiation with $1064 \mathrm{~nm}$ wavelength, $1.5 \mathrm{~W}$ output power, $100 \mathrm{~mJ}$ pulse energy, short pulse width and $15 \mathrm{~Hz}$ frequency. Laser was irradiated manually using a hand piece with fiber optic tip with $300 \mu \mathrm{m}$ diameter from $1 \mathrm{~mm}$ distance for 10 seconds using overlapping sweeping motion with a speed of $2 \mathrm{~mm} / \mathrm{second}$. The bonding agent and composite were applied as in the control group ${ }^{24}$.

Restored teeth were immersed in water and incubated at $37^{\circ} \mathrm{C}$ for 24 hours and were then polished using coarse to fine-grit polishing discs (Opti disc, Kerr, Hawe SA, Bioggio, Switzerland). The teeth were then subjected to 5000 thermal cycles between $5-55^{\circ} \mathrm{C}$ with a dwell time of 30 seconds and transfer time of 30 seconds. Next, the apices were sealed with wax. All parts of the teeth and cavity walls were coated with two layers of nail varnish except for $1 \mathrm{~mm}$ around restoration margins. The teeth were then immersed in $2 \%$ fuchsine (Merck, Darmstadt, Germany) at room temperature for 72 hours. Next, the teeth were sectioned into mesial and distal halves using a cutting machine and a diamond disc with $0.3 \mathrm{~mm}$ thickness. Microleakage at both sides was determined under a stereomicroscope at $\times 40$ magnification by the same operator twice and the greater value was reported as the amount of microleakage.

Microleakage was scored in occlusal and gingival margins as follows (Figure 1):

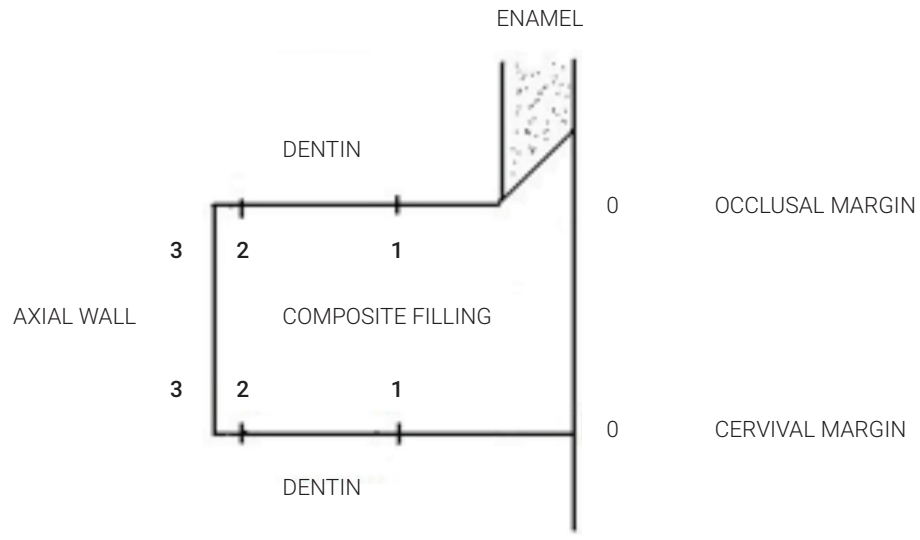

Figure 1. Schematic view of microleakage scores in the occlusal and gingival margins 


\section{0 : No dye penetration}

1: Dye penetration to half the gingival or occlusal wall

2: Dye penetration to more than half the gingival or occlusal wall but not reaching the axial wall

3: Dye penetration at the tooth-restoration interface reaching the axial wall

To assess the micromorphology of the resin-dentin interface under a scanning electron microscope (SEM), the slabs were wet-polished with 600, 800 and 1000 grit silicon carbide abrasive papers. After etching, the slabs were immersed in $5.25 \%$ sodium hypochlorite for 20 minutes and immersed in ascending concentrations of ethanol $(33,50,70,85,95$ and $100 \%)$ and were then dried in a critical point dryer. Dehydrated samples were mounted in aluminum stubs (3M, Sao Paulo, SP, Brazil) using conductive tape and were sputter-coated with gold-palladium alloy for 120 seconds (Bal-Tec, SCD, 005; Zurich, Switzerland). The samples were then evaluated under a SEM (Jeol, JXA840, Tokyo, Japan) and some selected areas at the resin-dentin interface were photographed at $\times 1000$ and $\times 2500$ magnifications (two photographs).

Data were analyzed using SPSS version 19 via descriptive statistics and Kruskal Wallis and Mann Whitney tests $(a=0.05)$.

\section{Results}

The results of Kruskal Wallis test showed no significant difference in microleakage at the occlusal and cervical margins among the three groups ( $P>0.05$, Table 1$)$. The Mann Whitney test showed that in all groups, microleakage at the cervical margins was significantly greater than that at the occlusal margins $(P=0.000)$.

Figures 2 to 4 show selected SEM micrographs of the micromorphology of the resin-dentin interface in different groups.

Table 1. composition and instruction of adhesive system used in the study.

\begin{tabular}{|c|c|c|}
\hline Adhesive agents & composition & Instructions for use \\
\hline $\begin{array}{c}\text { Adper Single Bond } 2 \\
\text { (3M ESPE, St Paul, MN, USA) }\end{array}$ & $\begin{array}{l}\text { Ethyl alcohol, Bis-GMA, silane- } \\
\text { treated silica, 2-hydroxyethyl } \\
\text { methacrylate (HEMA), glycerol } \\
\text { 1,3-dimethacrylate, diurethane } \\
\text { dimethacrylate, copolymer of } \\
\text { acrylic and itaconic acids }\end{array}$ & $\begin{array}{l}\text { Apply two consecutive coats of } \\
\text { adhesive to the tooth surface } \\
\text { with gentle agitation for } 15 \\
\text { seconds; gently air thin; light } \\
\text { cure for } 10 \text { seconds }\end{array}$ \\
\hline $\begin{array}{c}\text { OptiBond Solo } \\
\text { (Kerr SPA, Salerno, Italy) }\end{array}$ & $\begin{array}{c}\text { Bis-GMA, GPDM, GDMA, HEMA, } \\
\text { Ethyl alcohol, mono and } \\
\text { difunctional } \\
\text { methacrylate monomers, CQ, } \\
\text { fumed } \\
\text { Silica, barium aluminum } \\
\text { borosilicate } \\
\text { glass, sodium hexafluorosilicate }\end{array}$ & $\begin{array}{l}\text { Apply the adhesive and rub for } 15 \mathrm{~s} \\
\text { and dry for } 3 \mathrm{~s} \text {. Light cure for } 20 \mathrm{~s}\end{array}$ \\
\hline
\end{tabular}



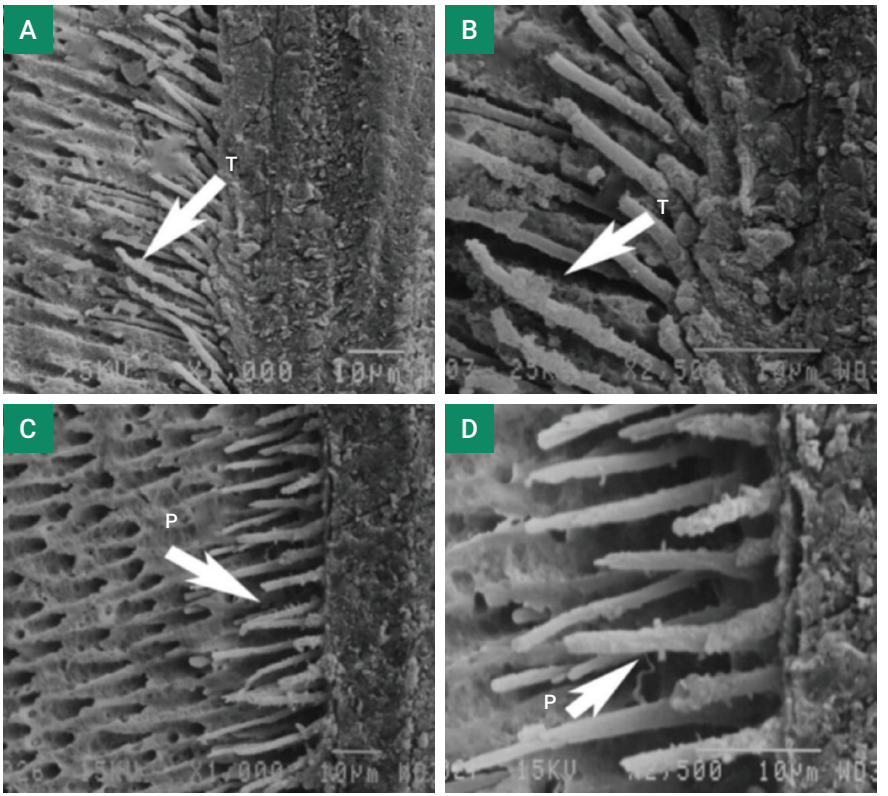

Figure 2. Selected SEM micrographs of resin-dentin interface in the control group; (A) Single Bond at x1000 magnification; (B) Single Bond at $\times 2500$ magnification; (C) OptiBond at x1000 magnification; (D) OptiBond at $\times 2500$ magnification. Conical resin tags with a rough surface $(T)$ and a few accessory canals filled with resin $(P)$ are also seen.
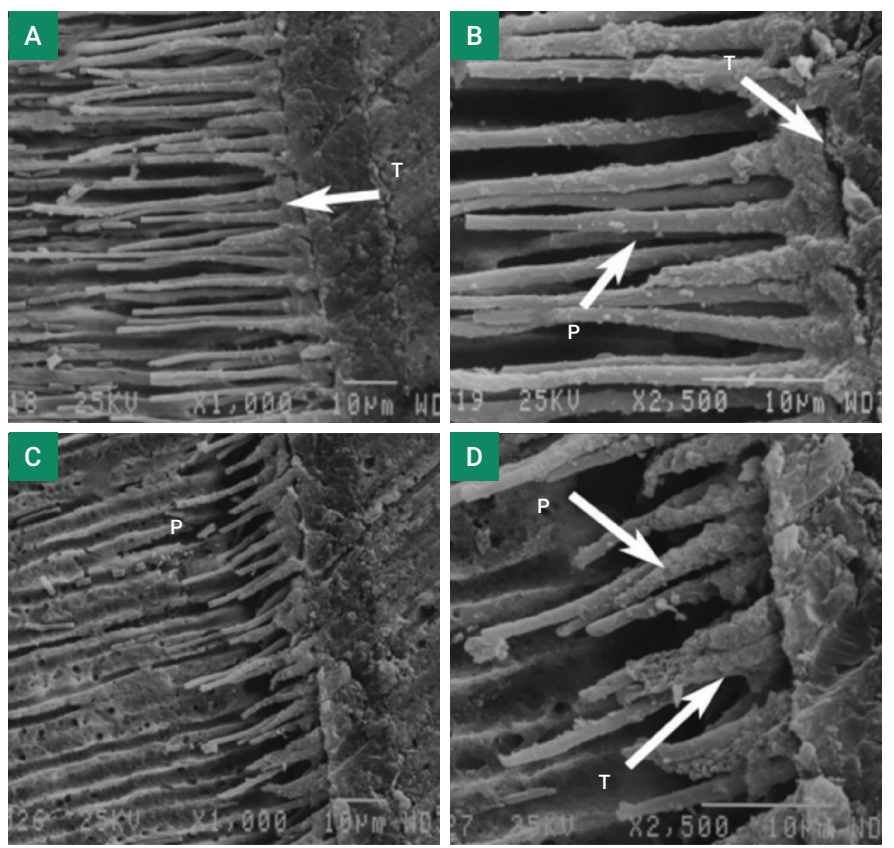

Figure 3. Selected SEM micrographs of resin-dentin interface after the application of bromelain (A) Single Bond at x1000 magnification; (B) Single Bond at x2500 magnification; (C) OptiBond at x1000 magnification; (D) OptiBond at $\times 2500$ magnification. Hybrid layer in this group was thicker than that in the other two groups. The resin tags were thicker and conical in shape $(T)$. Spherical residues were seen on resin tags, which are probably formed by slight penetration of resin into accessory canals in dentin $(P)$. 

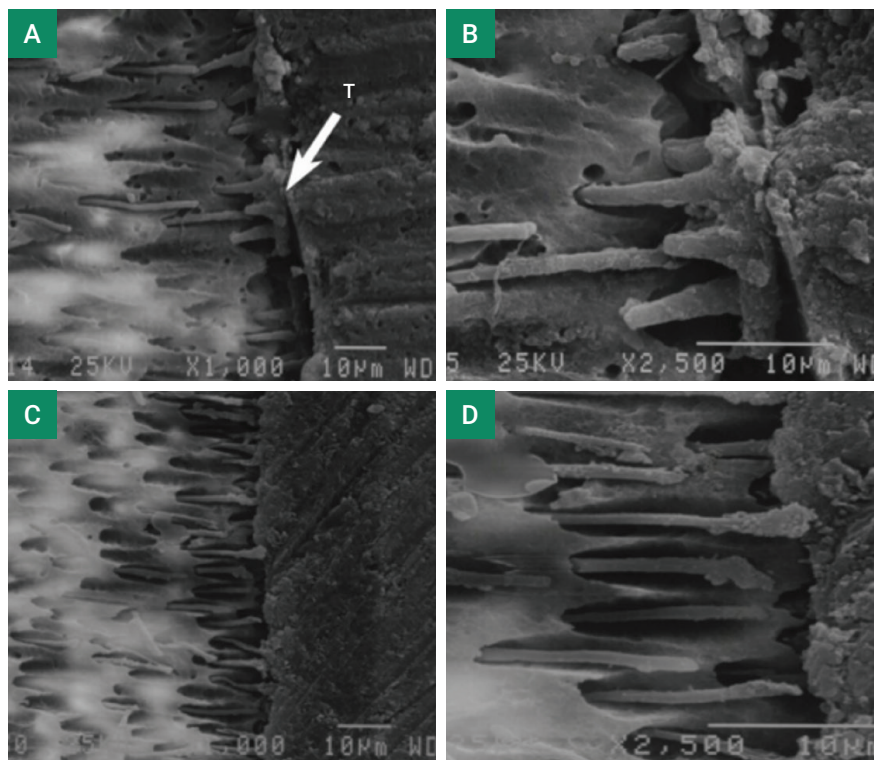

Figure 4. Selected SEM micrographs of resin-dentin interface after Nd:YAG laser irradiation; (A) Single Bond at x1000 magnification; (B) Single Bond at x2500 magnification; (C) OptiBond at x1000 magnification; (D) OptiBond at $\times 2500$ magnification. Hybrid layer was formed in limited areas. Resin tags were scarce and irregularly distributed $(\mathrm{T})$.

Table 2. Score of microleakage in the study groups

\begin{tabular}{|c|c|c|c|c|c|c|}
\hline \multirow{2}{*}{ Margin } & \multirow{2}{*}{ Groups } & \multicolumn{4}{|c|}{ Microleakage score } & \multirow{2}{*}{ P-value } \\
\hline & & 0 & 1 & 2 & 3 & \\
\hline \multirow{3}{*}{$\begin{array}{l}\text { Occlusal } \\
\text { margin }\end{array}$} & Control $^{\mathrm{A}}$ & $38(95 \%)$ & $2(5 \%)$ & 0 & 0 & \multirow{3}{*}{0.362} \\
\hline & $\mathrm{Br}^{\mathrm{A}}$ & $39(97.5 \%)$ & $1(2.5 \%)$ & 0 & 0 & \\
\hline & $\mathrm{Nd}^{\mathrm{A}}$ & $40(100 \%)$ & 0 & 0 & 0 & \\
\hline \multirow{3}{*}{$\begin{array}{l}\text { Cervical } \\
\text { margin }\end{array}$} & Control $^{\mathrm{B}}$ & $26(65 \%)$ & $10(25 \%)$ & $2(5 \%)$ & $2(5 \%)$ & \multirow{3}{*}{0.147} \\
\hline & $\mathrm{Br}^{\mathrm{B}}$ & $34(85 \%)$ & $3(7.5 \%)$ & $3(7.5 \%)$ & 0 & \\
\hline & $\mathrm{Nd}^{\mathrm{B}}$ & $29(72.5 \%)$ & $6(15 \%)$ & $3(7.5 \%)$ & $2(5 \%)$ & \\
\hline
\end{tabular}

Comparisons between margins are coded by A and B. Comparisons between assessment points in each group (Kruskal Wallis) are coded by uppercase letters. Similar uppercase letters indicate statistically similar means.

\section{Discussion}

Pulpal response to restorative material is related to marginal leakage. If a dentin adhesive system does not adhere intimately to the dentin substrate,an interfacial gap eventually develops,and bacteria are able to penetrate through this gap ${ }^{3}$.

Type of solvent present in the bonding system is an important factor directly affecting the penetration ability of etch and rinse adhesive systems into dentin substrate. By an increase in penetration depth of solvent into etched dentin, hydrophilic properties decrease and chemical integration between hydrophilic dentin and hydrophobic resin improves, resulting in a stronger bond ${ }^{1}$. Thus, in this study, adhesive systems with the same solvent (ethanol) were selected. However, it should be noted that since both 
adhesive systems are commercially available, the amount of solvent and other resin components in chemical composition of the two systems are different.

In this study, application of $5 \%$ bromelain did not cause a significant reduction in microleakage, which is in contrast to the results of previous studies, ${ }^{3,17}$. Dayem et al. reported that application of bromelain on etched dentin significantly decreased leakage; they attributed this finding to the ability of bromelain to remove collagen network of etched dentin ${ }^{1,3}$. Chauhan et al. reported similar results. They stated that bromelain increases the permeability of dentin substrate by depletion of collagen from the acid-etched surface and causes widening of dentinal tubules in the outer surface. It also increases the surface energy and penetration and infiltration of monomers into dentin ${ }^{17}$. Since hydroxyapatite has high and collagen has low surface energy, collagen removal from etched dentin decreases the organic content, increases the surface energy and changes the hydrophilic properties of dentin, causing better penetration of adhesive monomers into dentin ${ }^{3}$. Dayem and Tameesh ${ }^{3}$ in SEM assessment of bromelain group, represent that the orifices of the dentinal tubules look wider compared to that in Nd:YAG laser group ${ }^{3}$. In our study, in bromelain group, hybrid layer was thicker and resin tags were thicker and conical in shape. Also, slight penetration of resin into accessory canals in dentin was also noted (Figure 3). However, no statistically significant difference was found in marginal microleakage of bromelain and control groups, which may be due to the effect of other influential factors such as percentage and duration of use of bromelain. In this study, $5 \%$ bromelain was used for 30 seconds in order to simulate short clinical application and have the lowest possible toxicity while Chauhan et al, and Dayem et al. applied pure bromelain for one minute on dentin surfaces ${ }^{3,17}$.

On the other hand, by activation of matrix metalloproteinases in the collagen matrix, insoluble components may be broken down into small peptides and amino acids, eliminated from the hybrid layer and replaced with water. However, since the tested protocol does not change the hydrophilic nature of adhesive and solvent evaporation, it does not decrease the permeability of interface either. Thus, it cannot be expected that no leakage occurs in use of bromelain. Our results showed that proteolytic agents did not prevent adhesive monomer penetration, solvent evaporation or adhesive polymerization; otherwise, we would have noticed greater microleakage compared to that in the control group ${ }^{23}$.

Based on the results of this study, no significant difference was noted in microleakage of control and Nd:YAG laser groups. But studies have reported controversial results regarding the effect of Nd:YAG laser for dentin surface preparation prior to restoration of cavity. Some previous studies reported an increase in bond strength ${ }^{25}$ and a reduction in microleakage ${ }^{25}$. According to Dayem research, laser irradiation caused higher number of resin tags and better penetration of adhesive ${ }^{1}$ while Ribeiro et al. ${ }^{26}$ reported the greatest microleakage with the same laser irradiation parameter ${ }^{26}$. Castro et al. ${ }^{27}$ stated that due to the absence of significant structural changes in the hybrid layer, laser irradiation cannot increase the bond strength to etched dentin ${ }^{27}$. Some authors reported that application of laser prior to the use of adhesive system decreases the bond strength due to the obstruction of tubules and melting of dentin ${ }^{28}$.

Laser irradiation of dentin surface can increase the calcium and phosphorus content and decrease the concentration of oxygen in dentin and create a glossy surface. It can also cause thermal fusion, re-freezing and fusion of the smear layer 
and result in partial obstruction of dentinal tubules. Moreover, it can decrease the microbial count. Elimination of smear layer and microorganisms is favorable for the bonding process ${ }^{24}$. It appears that Nd:YAG laser irradiation results in formation of stronger bond by the adhesive system via fusion and re-crystallization of dentin apatites ${ }^{5}$, opening of tubules and elimination of smear layer ${ }^{1}$. In agreement with these findings, Gan et al. ${ }^{29}$, in 2016 used the same bonding agent and pulse energy of laser as in our study and reported removal of collagen fibrils from dentin surface and lower microleakage in assessment by attenuated total reflectance-Fourier transform infrared spectroscopy ${ }^{29}$.

Moreover, in addition to polymerization shrinkage and marginal gap, presence of higher water content, greater moisture and higher organic content in the gingival margin impair the bonding process and cause higher microleakage at this margin ${ }^{24}$.

Based on all the above, microleakage is expected to be lower in Nd:YAG laser group. But it should be noted that the interaction of laser with tooth structure is determined by laser irradiation parameters such as wavelength, laser energy, repetition rate, distance from the surface and optical properties of tissue. Different results in different studies may be due to variability in irradiation parameters and time of laser irradiation (before or after the bonding process) ${ }^{28}$.

Since in this study microleakage after surface preparation with $5 \%$ bromelain and $\mathrm{Nd}$ :YAG laser was not significantly different from that in the control group, the null hypothesis was accepted. Further studies using higher percentage of bromelain and Nd:YAG laser with other irradiation parameters are required to confirm or refute the results of this study. Due to the limitation of technique that used to evaluate the microleakage, Additional work is also needed to determine the effect of this protocols on dentin bonding.

Within the limitations of this study, application of $5 \%$ bromelain and Nd:YAG laser for deproteinization of etched dentin surface had no significant effect on microleakage of etch and rinse adhesive systems.

\section{References}

1. Dayem RN. Assessment of the penetration depth of dental adhesives through deproteinized acid etched dentin using neodymium: yttrium-aluminum-garnet laser and sodium hypochlorite. Lasers Med Sci. 2010 Jan;25(1):17-24. doi: 10.1007/s10103-008-0589-4.

2. Dayem RN. A novel method for removing the collagen network from acid-etched dentin by neodymium: yttrium-aluminum-garnet laser. Lasers Med Sci. 2009 Jan;24(1):93-9.

3. Dayem RN, Tameesh MA. A new concept in hybridization: Bromelain enzyme for deproteinizing dentin before application of adhesive system. Contemp Clin Dent. 2013 Oct;4(4):421-6. doi: 10.4103/0976-237X.123015.

4. Xu C, Wang Y. Cross-linked demineralized dentin maintains its mechanical stability when challenged by bacterial collagenase. J Biomed Mater Res B Appl Biomater. 2011 Feb;96(2):242-8. doi: 10.1002/jbm.b.31759.

5. Scheffel DL, Hebling J, Scheffel RH, Agee KA, Cadenaro M, Turco G, et al. Stabilization of dentin matrix after cross-linking treatments, in vitro. Dent Mater. 2014 Feb;30(2):227-33. doi: 10.1016/j.dental.2013.11.007. 
6. Spencer P, Ye Q, Park J, Topp EM, Misra A, Marangos O, et al. Adhesive/dentin interface: the weak link in the composite restoration. Ann Biomed Eng. 2010 Jun;38(6):1989-2003. doi: 10.1007/s10439-010-9969-6.

7. Scheffel DLS, Hebling J, Scheffel RH, Agee K, Turco G, de Souza Costa CA, et al. Inactivation of matrix-bound matrix metalloproteinases by cross-linking agents in acid-etched dentin. Oper Dent. 2014 Mar-Apr;39(2):152-8. doi: 10.2341/12-425-L.

8. Liu Y, Tjäderhane L, Breschi L, Mazzoni A, Li N, Mao J, Pashley DH, et al. Limitations in bonding to dentin and experimental strategies to prevent bond degradation. J Dent Res. 2011 Aug;90(8):953-68. doi: $10.1177 / 0022034510391799$

9. Pashley DH, Tay FR, Breschi L, Tjäderhane L, Carvalho RM, Carrilho M, et al. State of the art etch-and-rinse adhesives. Dent Mater. 2011 Jan;27(1):1-16. doi: 10.1016/j.dental.2010.10.016.

10. Carrilho M, Geraldeli S, Tay F, de Goes MF, Carvalho RM, Tjäderhane L, et al. In vivo preservation of the hybrid layer by chlorhexidine. J Dent Res. 2007 Jun;86(6):529-33.

11. Zhang S-c, Kern M. The role of host-derived dentinal matrix metalloproteinases in reducing dentin bonding of resin adhesives. Int J Oral Sci. 2009 Dec; 1(4):163-76. doi: 10.4248/IJOS.09044..

12. Summitt JB, Robbins JW, Hilton TJ, Schwartz RS. Fundamentals of operative dentistry: a contemporary approach. Quintessence Pub.; 2006.

13. Lu S, Zhao S-j, Gao Y, Sun Y, Li X, Chen J-h. Proteoglycans affect monomer infiltration in the etch-and-rinse bonding technique. Dent Mater. 2014 Nov;30(11):e289-99. doi: 10.1016/j.dental.2014.05.015.

14. Breschi L, Lopes M, Gobbi P, Mazzotti G, Falconi M, Perdigão J. Dentin proteoglycans: an immunocytochemical FEISEM study. J Biomed Mater Res. 2002 Jul;61(1):40-6.

15. Breschi L, Gobbi P, Lopes M, Prati C, Falconi M, Teti G, et al. Immunocytochemical analysis of dentin: A double-labeling technique. J Biomed Mater Res A. 2003 Oct 1;67(1):11-7.

16. Shin TP, Yao X, Huenergardt R, Walker MP, Wang Y. Morphological and chemical characterization of bonding hydrophobic adhesive to dentin using ethanol wet bonding technique. Dent Mater. 2009 Aug;25(8):1050-7. doi: 10.1016/j.dental.2009.03.006

17. Chauhan K, Basavanna RS, Shivanna V. Effect of bromelain enzyme for dentin deproteinization on bond strength of adhesive system. J Conserv Dent. 2015 Sep-Oct;18(5):360-3. doi: 10.4103/0972-0707.164029

18. Han B, Jaurequi J, Tang BW, Nimni ME. Proanthocyanidin: a natural crosslinking reagent for stabilizing collagen matrices. Journal of Biomedical Materials Research Part A. 2003;65(1):118-124.

19. Al-Ammar A, Drummond JL, Bedran-Russo AK. The use of collagen cross-linking agents to enhance dentin bond strength. J Biomed Mater Res A. 2003 Apr 1;65(1):118-24.

20. Bedran-Russo AKB, Pashley DH, Agee K, Drummond JL, Miescke KJ. Changes in stiffness of demineralized dentin following application of collagen crosslinkers. J Biomed Mater Res B Appl Biomater. 2008 Aug;86(2):330-4.

21. Castellan CS, Bedran-Russo AK, Karol S, Pereira PNR. Long-term stability of dentin matrix following treatment with various natural collagen cross-linkers. J Mech Behav Biomed Mater. 2011 Oct;4(7):1343-50. doi: 10.1016/j.jmbbm.2011.05.003.

22. Macedo G, Yamauchi M, Bedran-Russo A. Effects of chemical cross-linkers on caries-affected dentin bonding. J Dent Res. 2009 Dec;88(12):1096-100. doi: 10.1177/0022034509351001

23. Hass V, Luque-Martinez IV, Gutierrez MF, Moreira CG, Gotti VB, Feitosa VP, et al. Collagen cross-linkers on dentin bonding: Stability of the adhesive interfaces, degree of conversion of the adhesive, cytotoxicity and in situ MMP inhibition. Dent Mater. 2016 Jun;32(6):732-41. doi: 10.1016/j.dental.2016.03.008.

24. Savadi Oskoee S1, Alizadeh Oskoee P, Jafari Navimipour E, Ahmad Ajami A, Pournaghi Azar F, Rikhtegaran S, et al. Comparison of the effect of $\mathrm{Nd}$ : YAG and diode lasers and photodynamic therapy on microleakage of class $\mathrm{V}$ composite resin restorations. J Dent Res Dent Clin Dent Prospects. 2013;7(2):74-80. doi: 10.5681/joddd.2013.013.. 
25. Wen X, Liu L, Nie X, Zhang L, Deng M, Chen Y. Effect of pulse Nd: YAG laser on bond strength and microleakage of resin to human dentine. Photomed Laser Surg. 2010 Dec;28(6):741-6. doi: 10.1089/pho.2009.2579.

26. Ribeiro CF, Anido AA, Rauscher FC, Yui KCK, Gonçalves SEDP. Marginal leakage in class $V$ cavities pretreated with different laser energy densities. Photomed Laser Surg. 2005 Jun;23(3):313-6.

27. Castro FL, Andrade MF, Hebling J, Lizarelli RF. Nd: YAG laser irradiation of etched/unetched dentin through an uncured two-step etch-and-rinse adhesive and its effect on microtensile bond strength. J Adhes Dent. 2012 Apr;14(2):137-45. doi: 10.3290/j.jad.a21854.

28. Marimoto A, Cunha L, Yui K, Huhtala MF, Barcellos DC, Prakki A, et al. Influence of Nd: YAG laser on the bond strength of self-etching and conventional adhesive systems to dental hard tissues. Oper Dent. 2013 Jul-Aug;38(4):447-55. doi: 10.2341/11-383-L

29. Gan J, Liu S, Zhou L, Wang Y, Guo J, Huang C. Effect of Nd: YAG Laser Irradiation Pretreatment on the Long-Term Bond Strength of Etch-and-Rinse Adhesive to Dentin. Oper Dent. 2017 Jan/Feb;42(1):62-72. doi: 10.2341/15-268-L. 